\section{Modeling Flower Bud Elongation in Easter Lily (Lilium longiflorum Thunb.) in Response to Temperature}

\author{
P.R. Fisher and J.H. Lieth \\ Department of Environmental Horticulture, University of California, Davis, \\ CA 95616-8587
}

\author{
R.D. Heins \\ Department of Horticulture, Michigan State University, East Lansing, \\ MI 48824-1325
}

Additional index words. decision support, bud length, bud development meter, simulation

\begin{abstract}
A model was developed to quantify the response of Easter lily ('Nellie White') flower bud elongation to average air temperature. Plants were grown in greenhouses set at $15,18,21,24$, or $27 \mathrm{C}$ after they had reached the visible bud stage. An exponential model fit the data with an $R^{2}$ of 0.996 . The number of days until open flowering could be predicted using the model because buds consistently opened when they were $16 \mathrm{~cm}$ long. The model was validated against data sets of plants grown under constant and varying greenhouse temperatures at three locations, and it was more accurate and mathematically simpler than a previous bud elongation model. Bud length can be used by lily growers to predict the average temperature required to achieve a target flowering date, or the flowering date at a given average temperature. The model can be implemented in a computer decisionsupport system or in a tool termed a bud development meter.
\end{abstract}

The Easter lily has a precise market window that varies from year to year depending on the date of Easter. Many Easter lily growers use a flower bud elongation model, the most widely used version of which was developed by Healy and Wilkins (1984), termed the "HW model," to help control flowering date by manipulating temperature. These authors modeled bud elongation in two linear phases, with a junction at the point where bud length reached $6 \mathrm{~cm}$. In a greenhouse validation trial (Fisher, 1995), we found a major bias in the predictions of the HW model, and also in predictions of an exponential function we fitted to their data. Near visible bud, the stage when flower buds first become externally visible, both models underpredicted the average temperature required to achieve a target flowering date. Required temperatures were overpredicted as the crop approached flowering.

Our objective was to develop a bud elongation model to dynamically simulate bud elongation in response to average greenhouse air temperature $(T)$ and other variables (Table 1 ). We aimed to validate the model under both constant and varying greenhouse temperatures. The model was designed to predict the re-

Received for publication 25 Sept. 1995. Accepted for publication 31 Jan. 1996. We thank Univ. Outreach at Michigan State Univ. and the California Association of Nurserymen for providing funding for this project. Thanks also to Niels Ehler, Poul Karlsen, and Michael Brogaard for their experimentation at the Royal Veterinary and Agriculture College in Copenhagen, Denmark. The cost of publishing this paper was defrayed in part by the payment of page charges. Under postal regulations, this paper therefore must be hereby marked advertisement solely to indicate this fact. quired $T$ to achieve a target flowering date or, alternatively, the number of days to first open flower $(D)$ for a given $T$ for use in a decisionsupport system (Fisher, 1995). A further goal was to develop a new bud development meter (Healy and Wilkins, 1984) to summarize model results as a tool for growers.

\section{Materials and Methods}

Model theory. An exponential function was used to describe flower bud length ( $B$ in $\mathrm{mm}$ ) at time $t$ (days) under constant temperature conditions, given an initial bud length measurement of $B_{0}(\mathrm{~mm})$ at time $t_{0}$ :

$B=B_{0} e^{k\left(t-t_{0}\right)}$

Healy and Wilkins (1984) found that bud elongation rate increased as temperature in-
Table 1. List of abbreviations and parameters. creased between 15 and 27C. To incorporate the temperature response, the rate parameter $k$ $\left(\right.$ day $\left.^{-1}\right)$ in Eq. [1] can be replaced by some function of temperature, $\mathrm{f}(T)$, so that Eq. [1] becomes

$B=B_{0} e^{\mathrm{f}(T)\left(t-t_{0}\right)}$

Easter lily flowers consistently open at some maximum bud length $\left(B_{f}\right.$, in $\mathrm{mm}$ ) of $\approx 160 \mathrm{~mm}$ (Healy and Wilkins, 1984). The number of days $(D)$ to the date when the first flower opens ( $t_{f}$, in days) for any value of $B$ can therefore be calculated as

$B_{f}=B e^{\mathrm{f}(T) D}$

and $D$ can be estimated by

$D=\ln \left(B_{f} / B\right) / \mathrm{f}(T)$

Similarly, $T$ can be calculated by algebraic manipulation of Eq. [4] if $D$ is given and the inverse of $\mathrm{f}(T)$ is known.

Experiment design: Calibration data set. Easter lily plants ('Nellie White' in all experiments) with clearly visible flower buds were selected from a commercial greenhouse on 15 Mar. 1994. Five plants per treatment were placed in Michigan State Univ. (MSU) greenhouses set at $15,18,21,24$, or $27 \mathrm{C}$ [actual daily temperatures were $15.5 \pm 0.2,18.3 \pm 0.1$, $21.2 \pm 0.1,24.3 \pm 0.1$, and $27.0 \pm 0.1 \mathrm{C}$ (mean \pm standard error), respectively]. Flower bud length of a single randomly selected bud was measured to the nearest millimeter on each plant three times per week. In all experiments, plants were inspected daily and the date on which the first flower opened on each plant ("open flower" stage) was recorded.

Fixed temperature settings: Validation data set 1. Plants were obtained from a commercial greenhouse on 8 Mar. 1995 immediately after the visible bud stage (which occurs when immature flower buds are externally visible without leaves being moved), and five plants per treatment were placed in MSU greenhouses set at 18,21,24, and 27C (actual daily temperatures $19.0 \pm 0.2,20.9 \pm 0.2,21.7 \pm 0.7$, and $27.7 \pm 1.3 \mathrm{C}$, respectively). An additional five plants were placed first at $18 \mathrm{C}$ until they were $60 \mathrm{~mm}$ long, then at $24 \mathrm{C}$. A further group

\begin{tabular}{|c|c|c|}
\hline Symbol & Description & Units \\
\hline$B$ & Flower bud length & $\mathrm{mm}$ \\
\hline$B_{O}$ & Initial bud length & $\mathrm{mm}$ \\
\hline$B_{f}$ & Final bud length & $\mathrm{mm}$ \\
\hline$c_{l}$ & Parameter in $\mathrm{f}(T)$ & day $^{-1}$ \\
\hline$c_{3}$ & Parameter in $\mathrm{f}(T)$ & $\mathrm{C}^{-2}$ day $^{-1}$ \\
\hline$D$ & Days to first open flower & days \\
\hline$k$ & Rate parameter in exponential bud length model & day $^{-1}$ \\
\hline $\mathrm{f}(T)$ & Function quantifying $k$ as a function of $T$ & day $^{-1}$ \\
\hline KVL & $\begin{array}{l}\text { Royal Veterinary and Agricultural Univ., } \\
\text { Copenhagen, Denmark }\end{array}$ & \\
\hline MSU & Michigan State Univ. & \\
\hline$t$ & Time & days \\
\hline$t_{f}$ & Time of first open flower & days \\
\hline$t_{o}$ & Time zero & days \\
\hline $\mathrm{T}$ & Average air temperature & ${ }^{\circ} \mathrm{C}$ \\
\hline UCD & Univ. of California at Davis & \\
\hline
\end{tabular}




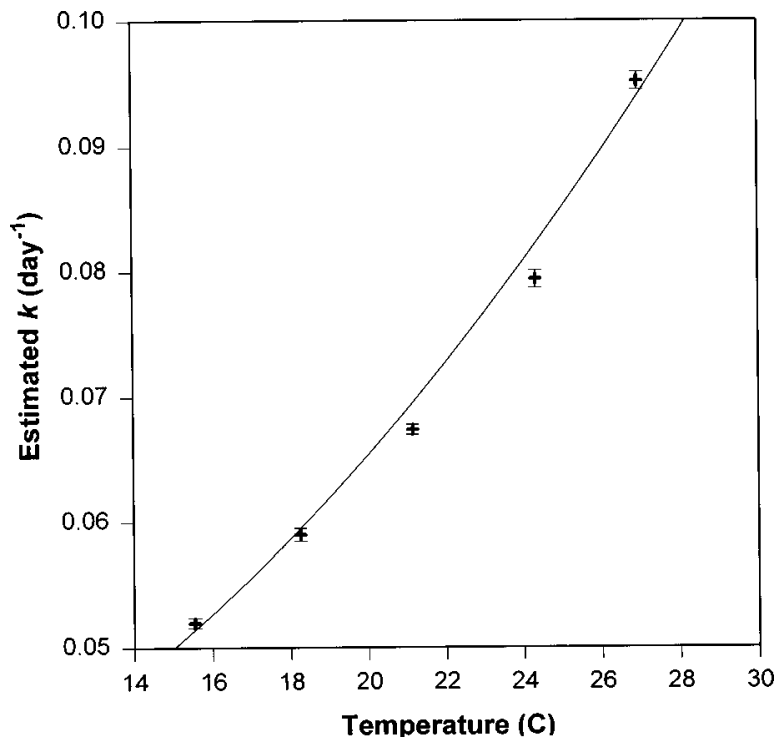

Fig. 1. Estimates of $k$, the rate parameter in Eq. [1], obtained using nonlinear regression to fit Eq. [1] separately to data from five temperature treatments in the calibration experiment $(+$ symbol, \pm asymptotic standard error) and the quadratic $\mathrm{f}(T)$ function (solid line).

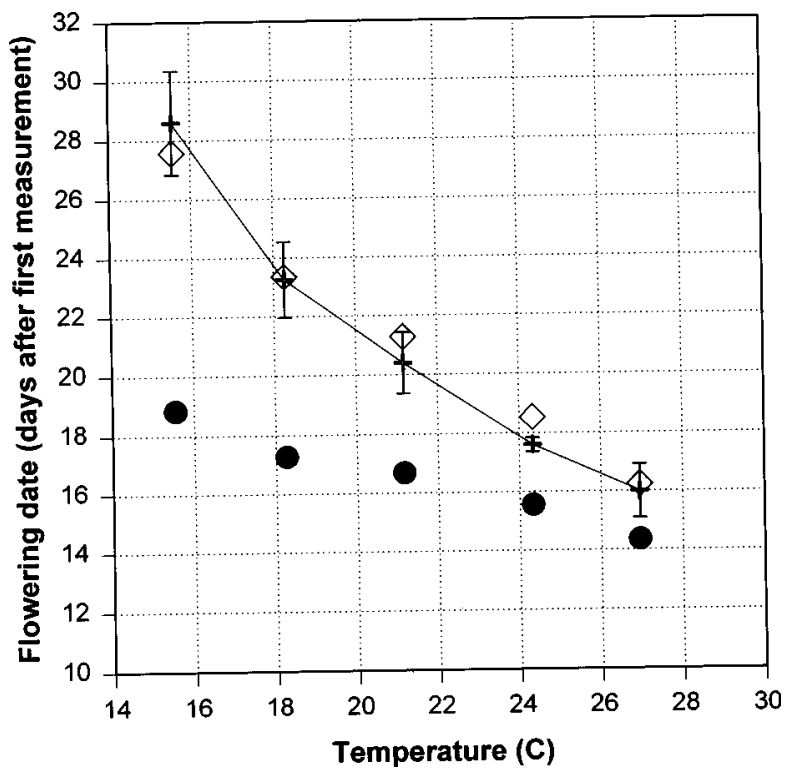

Fig. 3. Observed flowering dates $(+$, mean \pm standard error for five plants per treatment) at various temperatures in the calibration experiment, and the flowering dates predicted by the $(\diamond)$ exponential model and the (-) Healy-Wilkins model.

of five plants were moved from 24 to $18 \mathrm{C}$ when the flower buds were $60 \mathrm{~mm}$ long.

Variable temperature settings: Validation data set 2. Fifteen plants were grown in each of three greenhouses under varying temperatures between 10 and 27C during Mar. 1994 at MSU, the Univ. of California at Davis (UCD), and the Royal Veterinary and Agriculture Univ. at Copenhagen (KVL). Temperatures and the design were described in detail by Fisher (1995). Temperatures were set twice per week based on a development model (Fisher, 1995) that aimed to have plants in flower by target dates of 1 Apr. at UCD and 7 Apr. at MSU and KVL. Temperatures in these experiments were therefore variable (averaging $18.4 \pm 0.5 \mathrm{C}$, $19.9 \pm 0.8 \mathrm{C}$, and $15.3 \pm 0.4 \mathrm{C}$ each day for the UCD, MSU, and KVL experiments, respec- tively) and similar to those in a commercial greenhouse. Differences in average temperatures between locations existed because of differences in the timing of initial plant development stages and target flowering dates.

Variable temperature settings: Validation data set 3. Bud lengths were recorded on five plants grown at MSU and 15 plants grown at UCD during 1995, using the same design as validation data set 2 , with a target flowering date of 1 Apr. Daily temperatures in these experiments averaged $20.0 \pm 0.6 \mathrm{C}$ each day at MSU and 21.2 $\pm 0.4 \mathrm{C}$ at UCD.

Analysis. To calibrate the model, $k$ in Eq. [1] was estimated independently for each temperature treatment by fitting Eq. [1] to the calibration data set with the nonlinear regression procedure (PROC NLIN) in SAS (SAS
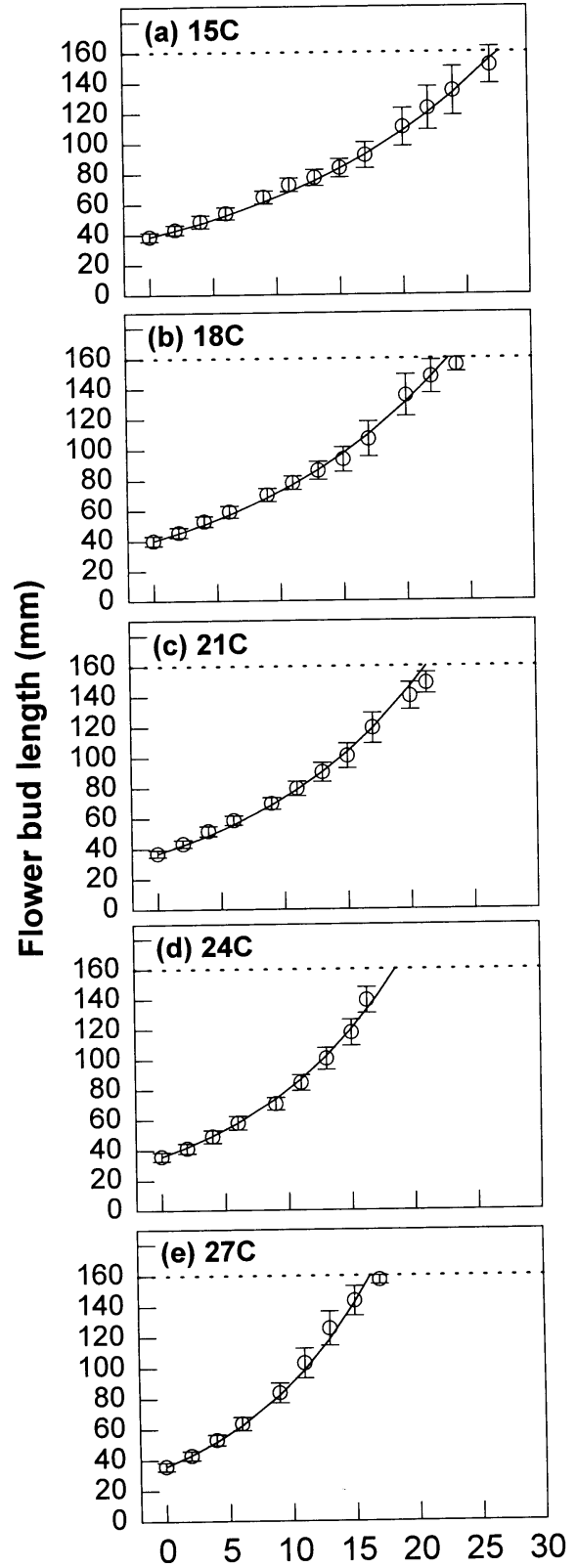

Days after first measurement

Fig. 2. Predicted (solid line) and observed $(\bigcirc$, mean \pm standard error) bud length for each treatment in the calibration experiment.

Institute, 1988). For each plant, $B_{0}$ and $t_{0}$ were assigned the values of the first recorded bud length and the first measurement date, respectively. A function $\mathrm{f}(T)$ was formulated based on the pattern of $k$ values across the range of temperatures and was fit to a data set of $k$ values estimated for each individual plant. $\mathrm{f}(T)$ was incorporated into Eq. [2], and it was fit simultaneously to the entire calibration data set using nonlinear regression to estimate the parameters in $\mathrm{f}(T)$. The final bud length at flower $\left(B_{f}\right)$ was then estimated by fitting Eq. [3] with nonlinear regression to the observed $D$ and $B$ in the calibration data set and setting the previously estimated $\mathrm{f}(T)$ parameters to constants.

To validate the model, the model error between predicted and observed $D$ was exam- 


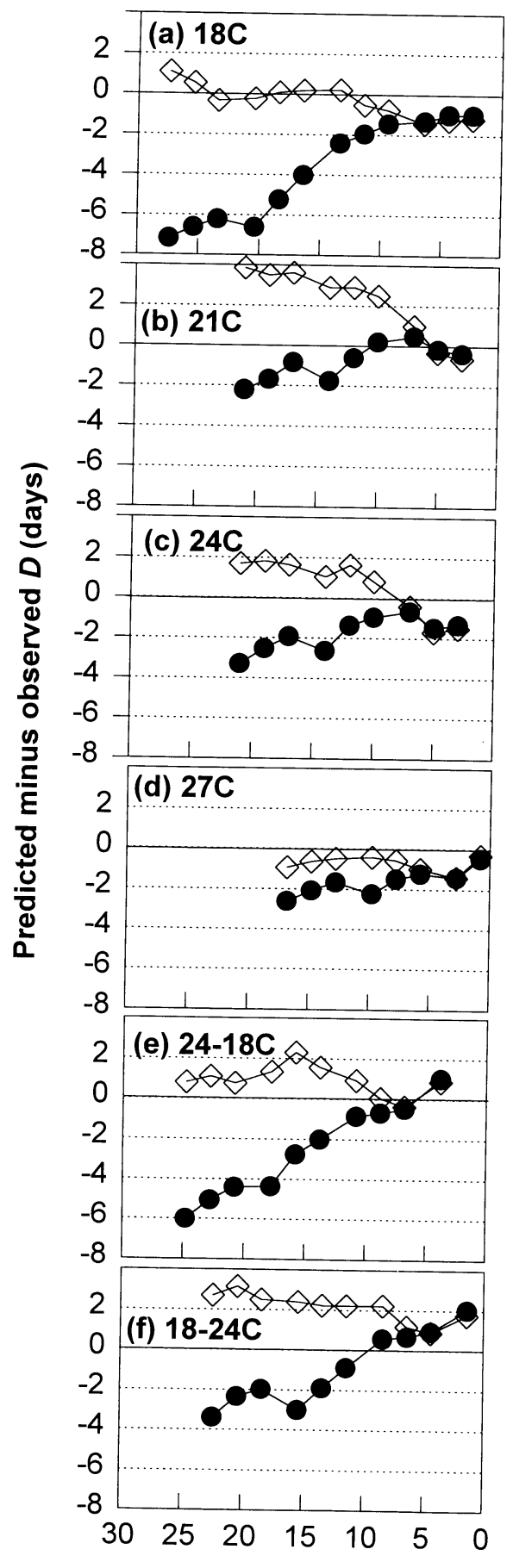

Days prior to flowering $(D)$

Fig. 4. Deviation between predicted and observed days to flower $(D)$ for the fixed temperature settings validation data set 1 . In graphs a-d, temperature settings were constant. In graphs e and f, plants were moved to a different temperature setting (18 to $24 \mathrm{C}$ and 24 to $18 \mathrm{C}$, respectively) when buds were $60 \mathrm{~mm}$ long ( 11 and 13 days before flowering, respectively). $\diamond=$ mode error for Eq. [4] and $\mathbf{Q}=$ error for the HealyWilkins model.

ined for the three validation data sets. For each measurement date and treatment, the temperature was averaged from the measurement date to flower, and $B$ was averaged across replicate plants. The average temperature and bud length were then inserted into Eq. [4] and the HW
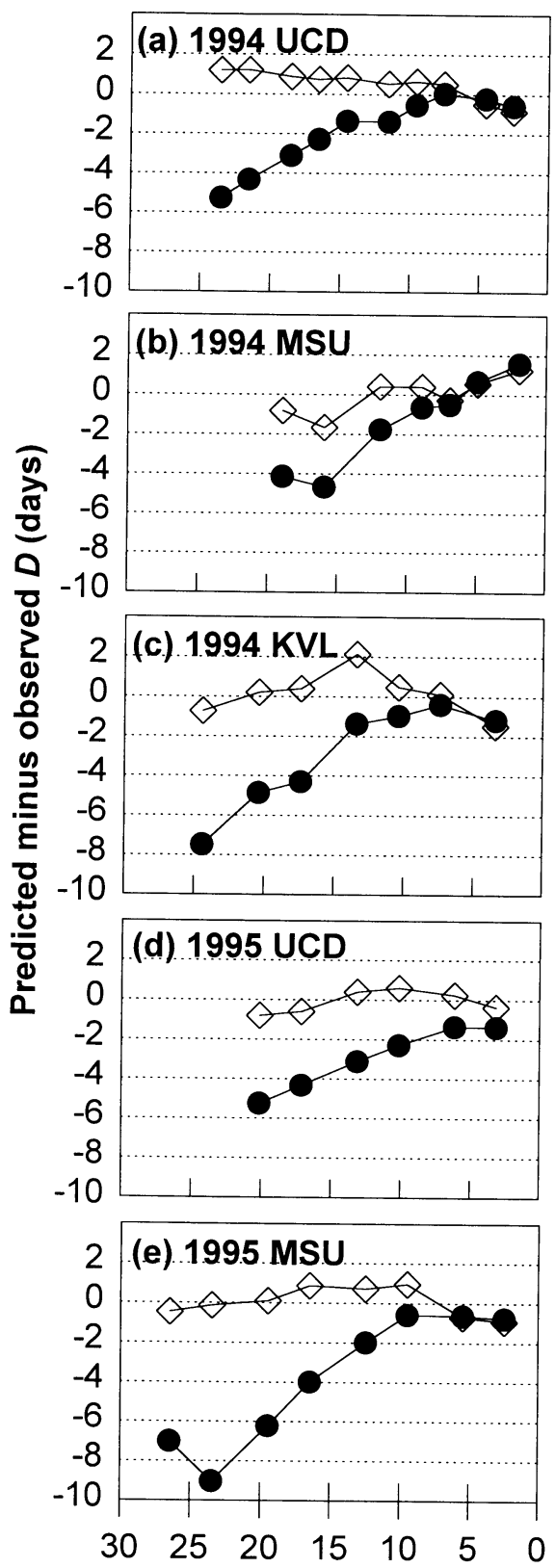

Days to flower $(D)$

Fig. 5. Deviation between predicted and observed days to flower $(D)$ for the validation data sets 2 $(\mathbf{a}-\mathbf{c})$ and 3 (d and $\mathbf{e})$ with variable temperature settings at three locations. $\diamond=$ model error for Eq. [4] and $\boldsymbol{0}$ error for the Healy-Wilkins model. $\mathrm{MSU}=$ Michigan State Univ., KVL = Royal Veterinary and Agriculture Univ. at Copenhagen, UCD = Univ. of California at Davis.

model. The deviation between predicted $D$ and observed $D$ was compared against observed $D$ to evaluate changes in model error over time.

\section{Results}

Model calibration. Bud elongation and development rates increased as temperature increased between 15 and $27 \mathrm{C}$, and the estimated $k$ values from Eq. [2] correspondingly increased with temperature (Fig. 1). A qua-

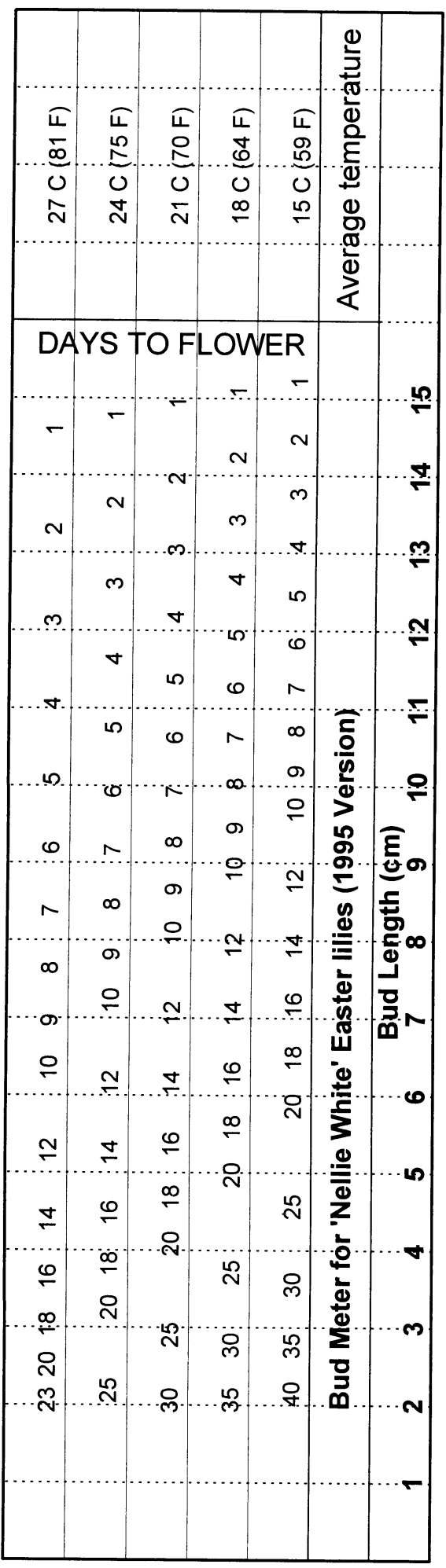

Fig. 6. Bud development meter computed from Eq. [4]. Instructions: Place left end of the meter at the base of the flower bud. Observe where the tip of the bud falls on the meter. Where the tip of the bud falls corresponds to the number of days to flower at the specified temperature.

dratic function $\left(k=c_{1}+c_{2} T+c_{3} T^{2}\right)$ was fit to the estimated $k$ values for each plant, using the stepwise procedure in the linear regression (PROC REG) procedure in SAS (SAS Institute, 1988), and the $c_{1}$ and $c_{3}$ parameters were statistically significant at $P \leq 0.05\left(r^{2}=0.952\right)$. 
This procedure resulted in $\mathrm{f}(T)=c_{1}+c_{3} T^{2}$ so that Eq. [2] became:

$B=B_{0} e^{\left(c_{1}+c_{3} T^{2}\right)\left(t-t_{0}\right)}$

where $c_{1}\left(\right.$ day $\left.^{-1}\right)$ and $c_{3}\left(\mathrm{C}^{-2}\right.$ day $\left.^{-1}\right)$ are constants. When Eq. [5] was fit to the entire data set simultaneously, $c_{1}$ and $c_{3}$ were estimated at $0.0313 \pm 0.0006$ day $^{-1}$ and $8.38 \times 10^{-5} \pm 1.6 \times$ $10^{-6} \mathrm{C}^{-2}$ day $^{-1}$ (estimate \pm asymptotic standard error), respectively. The resulting $R^{2}$ was 0.996 , and the exponential model closely fit the observed bud length data (Fig. 2).

The maximum bud length at flower $\left(B_{f}\right)$ from fitting Eq. [5] with nonlinear regression was estimated to be $159.8 \pm 1.0 \mathrm{~mm}$ (asymptotic standard error), which agreed with the HW model estimate of final bud length, and the $R^{2}$ was 0.988 . The predicted flowering date $\left(t_{f}\right)$, which occurred when predicted $B$ equaled $B_{f}$, was within one standard error of observed $t_{f}$ in all treatments except at $24 \mathrm{C}$ (Fig. 3). The maximum deviation between observed and predicted $t_{f}$ was 1 day for the $24 \mathrm{C}$ treatment. In comparison, the $t_{f}$ predicted by the HW model deviated from the observed $t_{f}$ by nearly 10 days at $15 \mathrm{C}$.

Model validation. The deviation between predicted and observed flowering date was generally within \pm 3 days for all three validation data sets (Figs. 4 and 5) using Eq. [4]. The only exception was an initial error of nearly 4 days at $21 \mathrm{C}$ in validation data set 1 (Fig. 4b). In comparison, the HW model showed a consistent tendency (Figs. 4 and 5) to underestimate $D$ until 10 days before flowering, with a deviation of up to 9 days.

\section{Discussion}

The model used here for relating Easter lily bud length to time and temperature (Eq. [5]) was more accurate than the HW model, particularly more than 10 days before flowering. The exponential model also was simpler, requiring only three parameters $\left(c_{1}, c_{3}\right.$, and $\left.B_{f}\right)$ compared with seven in the HW model. Prediction by the exponential model of the number of days to flowering, $D$, was generally within \pm 3 days, even as early as 4 weeks before flowering. This model performed well when validated against several greenhouse experiments.

The comparison between the exponential and HW model highlights potential problems that may arise from differences in plant temperature in greenhouse vs. growth chamber conditions. Data used by Healy and Wilkins (1984) were obtained from plants grown in growth chambers, where plant temperature is likely to differ from air temperature due to thermal heating from the lamps.

The exponential model provides horticulturally useful information. The model could be used to predict $B, T$, or $D$ by simple algebraic manipulation of Eq. [4]. A bud development meter was constructed (Fig. 6) for grower use based directly on the Healy and Wilkins (1984) tool, but incorporating the exponential model. The flower bud is placed onto the meter, and, based on observed bud length, $D$ can be predicted given the $T$ at the right-hand side of the meter. Mathematical equations were chosen that allow the model to be used for dynamic simulation, where changing temperature conditions can be incorporated into the model. This feature makes the exponential model suitable for incorporating into a computer decision-support system (Fisher, 1995).

\section{Literature Cited}

Fisher, P.R. 1995. Prediction and control of stem elongation and flowering in poinsettia and Easter lily. PhD Diss., Michigan State Univ., East Lansing. (Diss. Abstr. 96-05862.)

Healy, W.E. and H.F. Wilkins. 1984. Temperature effects on 'Nellie White' flower bud development. HortScience 19:843-844.

SAS Institute. 1988. SAS/STAT users guide, release 6.03 ed. SAS Inst., Cary, N.C. 